\title{
Retrospective cohort study of nanoparticle albumin-bound paclitaxel plus ramucirumab versus paclitaxel plus ramucirumab as second-line treatment in patients with advanced gastric cancer
}

\author{
Mashiro Okunaka', Daisuke Kotani ${ }^{2 *}$ (D, Ken Demachi ${ }^{1}$, Akihito Kawazoe ${ }^{2}$, Takayuki Yoshino²,
}

Toshikatsu Kawasaki ${ }^{1}$ and Kohei Shitara ${ }^{2}$

\begin{abstract}
Background: Nanoparticle albumin-bound paclitaxel (nab-PTX) has shown non-inferiority to paclitaxel (PTX) as second-line therapy for advanced gastric cancer (AGC) with fewer infusion-related reactions. The efficacy and safety of nab-PTX plus ramucirumab (RAM) was reported in a phase II trial; however, there is no randomized trial comparing this regimen with PTX plus RAM in patients with AGC. This retrospective study aimed to investigate the efficacy and safety of nab-PTX plus RAM versus PTX plus RAM in patients with AGC.

Methods: This study included patients with AGC who received nab-PTX plus RAM from September 2017 to January 2019 or PTX plus RAM from June 2015 to August 2017 as second-line chemotherapy in our hospital.

Results: A total of 113 and 138 patients who received nab-PTX plus RAM and PTX plus RAM, respectively, were analyzed. Median progression-free survival (PFS) was 3.9 months (95\% confidence interval [Cl]: 3.4-4.3) in the nabPTX plus RAM group and 3.9 months (95\% Cl: $3.1-4.7)$ in the PTX plus RAM group (hazard ratio [HR]: 1.08; $95 \%$ Cl: 0.83-1.40; $P=0.573$ ). Median overall survival (OS) was 10.9 months (95\% Cl: $9.3-12.7)$ in the nab-PTX plus RAM group and 10.3 months (95\% Cl: $8.5-12.0$ ) in the PTX plus RAM group (hazard ratio: $0.82 ; 95 \% \mathrm{Cl}: 0.61-1.10 ; P=$ 0.188). In patients with moderate/massive ascites, favorable outcomes for progression-free survival were observed in the nab-PTX plus RAM group compared with the PTX plus RAM group. Although anemia and fatigue (any grade) were more frequent in the nab-PTX plus RAM group, discontinuation of study treatment was not increased in the nab-PTX plus RAM group. There was no occurrence of hypersensitivity reaction in the nab-PTX plus RAM group, while two patients (1.4\%) experienced grade 3 hypersensitivity reactions in the PTX plus RAM group.
\end{abstract}

Conclusions: The combination of nab-PTX plus RAM showed a similar efficacy and safety profile to PTX plus RAM as second-line treatment for patients with AGC.

\footnotetext{
* Correspondence: dkotani@east.ncc.go.jp

${ }^{2}$ Department of Gastrointestinal Oncology, National Cancer Center Hospital

East, 6-5-1 Kashiwanoha, Kashiwa, Chiba 277-8577, Japan

Full list of author information is available at the end of the article
}

C C The Author(s). 2020 Open Access This article is licensed under a Creative Commons Attribution 4.0 International License, which permits use, sharing, adaptation, distribution and reproduction in any medium or format, as long as you give appropriate credit to the original author(s) and the source, provide a link to the Creative Commons licence, and indicate if changes were made. The images or other third party material in this article are included in the article's Creative Commons licence, unless indicated otherwise in a credit line to the material. If material is not included in the article's Creative Commons licence and your intended use is not permitted by statutory regulation or exceeds the permitted use, you will need to obtain permission directly from the copyright holder. To view a copy of this licence, visit http://creativecommons.org/licenses/by/4.0/. The Creative Commons Public Domain Dedication waiver (http://creativecommons.org/publicdomain/zero/1.0/) applies to the data made available in this article, unless otherwise stated in a credit line to the data. 


\section{Background}

Gastric cancer remains the third-leading cause of cancer-related mortality worldwide $[1,2]$.

While the combination of platinum agents plus fluoropyrimidine has been established as first-line chemotherapy for unresectable AGC [2-5], RAM (an anti-vascular endothelial growth factor receptor 2 antibody) plus PTX demonstrated survival benefit versus PTX alone as second-line chemotherapy in the RAINBOW trial $[6,7]$.

Nab-PTX is a 130-nm nanoparticle formulation that links albumin to PTX, rendering it soluble. Owing to its improved water solubility, nab-PTX is free of polyethoxylated castor oil, which minimizes the risk of hypersensitivity reactions without premedication [8-11]. Furthermore, as this formulation does not require the use of hydrated alcohol as a solvent, it can be used in patients with alcohol intolerance. A recent randomized phase III trial (ABSOLUTE) showed that weekly nabPTX was non-inferior to weekly PTX in terms of OS, with a lower incidence of hypersensitivity reactions [12]. This evidence led to the approval of weekly nab-PTX in Japan in August 2018. In addition, a phase II trial investigating the combination therapy of nab-PTX plus RAM showed promising activity and manageable toxicity in patients with previously treated AGC [13]. Based on these results, nab-PTX plus RAM is considered an option for second-line chemotherapy in patients with AGC $[2,3]$. However, there is no randomized study comparing nab-PTX plus RAM versus PTX plus RAM. Therefore, the aim of this study was to investigate the efficacy and safety of nab-PTX plus RAM compared with PTX plus RAM as second-line chemotherapy in patients with AGC in clinical practice.

\section{Methods}

\section{Study design and patients}

We retrospectively reviewed the medical records of consecutive patients with AGC who received nab-PTX plus RAM or PTX plus RAM at the National Cancer Center Hospital East, Kashiwa, Japan. The study protocol of this retrospective analysis was approved by the institutional review board of the National Cancer Center Hospital East. Informed consent requirement was waived due to the study's observational retrospective design, with opt-out opportunity provided at the institution's website.

The eligibility criteria for patients were as follows: aged $\geq 18$ years; diagnosed with histologically confirmed unresectable AGC; having history of previous treatment with fluoropyrimidine-containing first-line chemotherapy; received concurrent treatment with nab-PTX plus RAM from September 2017 to January 2019 or PTX plus RAM from June 2015 to August 2017.
The main exclusion criteria were as follows: other histology; histologically proven neuroendocrine carcinoma; treatment with nab-PTX plus RAM or PTX plus RAM as third or later line; and history of previous treatment with taxanes.

\section{Study procedures}

The nab-PTX plus RAM regimen consisted of nab-PTX 100 $\mathrm{mg} / \mathrm{m}^{2}$ intravenously over $30 \mathrm{~min}$ on days 1,8 , and 15 plus RAM $8 \mathrm{mg} / \mathrm{kg}$ intravenously on days 1 and 15 in a 28-day cycle. Premedication was only chlorpheniramine $5 \mathrm{mg}$ before RAM infusion on days 1 and 15 (https://www.accessdata.fda. gov/drugsatfda_docs/label/2013/021660s037lbl, https:/www. ema.europa.eu/en/medicines/human/EPAR/abraxane). The PTX plus RAM regimen consisted of PTX $80 \mathrm{mg} / \mathrm{m}^{2}$ intravenously over $30 \mathrm{~min}$ after premedication with dexamethasone $6.6 \mathrm{mg}$, chlorpheniramine $5 \mathrm{mg}$, and famotidine $20 \mathrm{mg}$ on days 1,8 , and 15 plus RAM 8 $\mathrm{mg} / \mathrm{kg}$ intravenously on days 1 and 15 in a 28-day cycle. Dose modification and interruption of treatment were decided by each investigator based on the criteria reported in clinical trials $[6,13]$.

The following baseline characteristics were collected for each patient: age, sex, Eastern Cooperative Oncology Group performance status, history of previous gastrectomy, history of adjuvant chemotherapy, time to progressive disease during first-line chemotherapy, human epidermal growth factor receptor 2 status, histology, metastatic sites, and amount of ascites.

\section{Outcomes}

PFS was defined as time from the initiation of study treatment to disease progression or death from any cause. OS was defined as time from the initiation of study treatment to death due from any cause. Overall response rate (ORR) was defined as the proportion of patients who had a complete or partial response to the study treatment, and disease control rate (DCR) was defined as the proportion of patients who had a complete response, partial response or stable disease lasting $>6$ weeks from the initiation of study treatment. Tumor response was assessed by each investigator in accordance with the Response Evaluation Criteria in Solid Tumors version 1.1. Adverse events were graded in accordance with the Common Terminology Criteria for Adverse Events version 4.03 [14]. The amount of ascites was defined using computed tomography as follows: none, small (limited to the pelvic cavity or around the liver), moderate (neither small nor massive), or massive (continuous ascites from the surface of the liver to the pelvic cavity). These definitions were used in previous studies [15]. 


\section{Statistical analysis}

PFS and OS were compared between treatment groups using the log-rank test with a two-sided significance level of $P=0.05$. HR and corresponding 95\% CI were determined using a Cox proportional hazards model. Survival curves were generated using Kaplan-Meier estimates. ORR, DCR, and safety analyses between treatment groups were performed using Fisher's exact test. Follow-up time was defined as time from the initiation of study treatment until the last follow-up date for censored cases. Statistical analyses were performed using the IBM SPSS statistics version 22.0 (IBM Corp, Armonk, NY, USA) software, and two-sided $P<0.05$ denote statistically significant differences.

\section{Results}

\section{Patients}

A total of 131 and 193 patients received nab-PTX plus RAM and PTX plus RAM, respectively. Eighteen and 55 patients were excluded from the nab-PTX plus RAM and PTX plus RAM groups, respectively. Finally, 113 and 138 patients in the nab-PTX plus RAM and PTX plus RAM groups, respectively, were analyzed (Fig. 1). Baseline characteristics were generally well balanced between the two groups. Although the proportion of patients with ECOG PS 0 or HER2 negative were numerically higher, there were no significant differences (Table 1). Of the patients, 94.1 and $94.2 \%$ had received platinum agents in the nab-PTX plus RAM and PTX plus RAM groups, respectively. At the time of analysis in December 2019, the median follow-up was 16.8 and 37.9 months in the nab-PTX plus RAM and PTX plus RAM groups, respectively. Of the patients, 75.2 and $58.0 \%$ in the nab-PTX plus RAM and PTX plus RAM groups, respectively, received subsequent antitumor therapy, including anti-programmed cell death 1/programmed cell death 1 ligand 1 (anti-PD-1/PD-L1) inhibitor (57.5\% vs. 26.8\%, respectively), irinotecan ( $31.9 \%$ vs. $47.1 \%$, respectively), platinum re-challenge $(7.1 \%$ vs. $18.1 \%$, respectively), and investigational agents in clinical trials (22.1\% vs. $20.3 \%$, respectively,) (Table S1).

\section{Efficacy}

The median PFS was 3.9 months (95\% CI: 3.4-4.3 months) in the nab-PTX plus RAM group and 3.9 months (95\% CI: 3.1-4.7 months) in the PTX plus RAM group. PFS was comparable between the two groups (HR: 1.08; 95\% CI: 0.83-1.40; $P=0.573$ ) (Fig. 2a). The median OS was 10.9 months (95\% CI: 9.3-12.7 months) in the nab-PTX plus RAM group and 10.3 months (95\% CI: 8.5-12.0 months) in the PTX plus RAM group. There was no significant difference between the two groups (HR 0.82; 95\% CI: 0.61-1.10; $P=0.188$ ) (Fig. 2b). The results of the subgroup analyses for PFS and OS are shown in Fig. 3. Patients with moderate or massive ascites showed a trend toward favorable outcomes for PFS in the nab-PTX plus RAM group ( $P$ for interaction $=$ 0.051 ), whereas there was no obvious trend observed for OS. Most of the other subgroups showed consistent results between PFS and OS.

Eighty-three and 106 patients had measurable lesions in the nab-PTX plus RAM and PTX plus RAM groups, respectively. Among these patients, 28 and 29 patients in

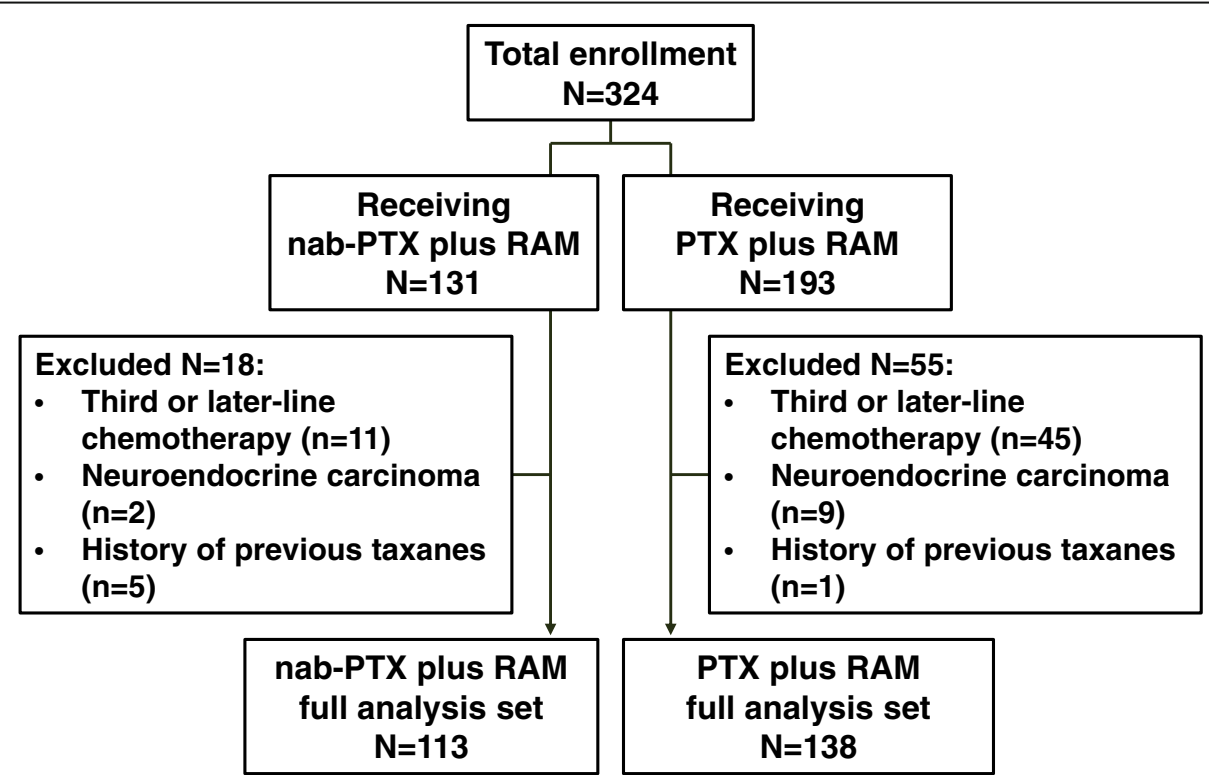

Fig. 1 CONSORT diagram. Among 324 patients, 131 patients received nab-PTX plus RAM chemotherapy, and 193 patients received PTX plus RAM chemotherapy. Finally, 113 and 138 patients in the nab-PTX plus RAM and PTX plus RAM groups, respectively, were analyzed 
Table 1 Patient characteristics

\begin{tabular}{|c|c|c|c|c|c|c|}
\hline & & nab-PTX pl & & PTX plus $R$ & & $P$ value \\
\hline & & $N=113$ & $\%$ & $N=138$ & $\%$ & \\
\hline Age & Median (range) & $67(25-84)$ & & $69(40-85)$ & & 0.16 \\
\hline & $>65$ & 71 & 62.8 & 96 & 69.6 & 0.261 \\
\hline Sex & Male & 78 & 69 & 88 & 63.8 & 0.381 \\
\hline & Female & 35 & 31 & 50 & 36.2 & 0.381 \\
\hline ECOG PS & 0 & 85 & 75.2 & 88 & 63.8 & 0.051 \\
\hline & 1 & 25 & 22.1 & 43 & 31.2 & 0.109 \\
\hline & $\geq 2$ & 3 & 2.7 & 7 & 5.1 & 0.261 \\
\hline Previous gastrectomy & Yes & 35 & 31 & 41 & 29.7 & 0.828 \\
\hline & No & 78 & 69 & 97 & 70.3 & 0.828 \\
\hline Recurrence during adjuvant chemotherapy & & 6 & 5.3 & 8 & 5.8 & 0.867 \\
\hline Time to progressive disease on first-line therapy & $\leq 6$ months & 75 & 66.4 & 78 & 56.5 & 0.112 \\
\hline & $>6$ months & 38 & 33.6 & 60 & 43.5 & 0.112 \\
\hline HER2 & Positive & 13 & 11.5 & 23 & 16.7 & 0.246 \\
\hline & Negative & 99 & 87.6 & 112 & 81.1 & 0.165 \\
\hline & Unknown & 1 & 0.9 & 3 & 2.2 & 0.39 \\
\hline Histology & Diffuse & 69 & 61.1 & 82 & 59.4 & 0.792 \\
\hline & Intestinal & 43 & 38.1 & 52 & 37.7 & 0.952 \\
\hline & Mix, Missing & 1 & 0.9 & 4 & 2.9 & 0.254 \\
\hline Number of metastatic sites & $0-1$ & 60 & 54 & 62 & 44.9 & 0.198 \\
\hline & 2 & 33 & 28.3 & 48 & 36.2 & 0.347 \\
\hline & $\geq 3$ & 20 & 17.7 & 28 & 18.9 & 0.604 \\
\hline Metastatic site & Liver & 32 & 28.3 & 46 & 33.3 & 0.393 \\
\hline & Lung & 18 & 15.9 & 19 & 13.8 & 0.631 \\
\hline & Lymph node & 54 & 47.8 & 74 & 53.6 & 0.358 \\
\hline & Peritoneum & 70 & 61.9 & 80 & 58 & 0.523 \\
\hline & Others & 13 & 11.5 & 26 & 18.8 & 0.11 \\
\hline Prior therapy & Fluoropyrimidine & 113 & 100 & 138 & 100 & - \\
\hline & Platinum & 107 & 94.7 & 130 & 94.2 & 0.867 \\
\hline & Trastuzumab & 10 & 8.8 & 21 & 15.2 & 0.127 \\
\hline Ascites & None & 59 & 52.2 & 75 & 54.3 & 0.736 \\
\hline & Small & 22 & 19.5 & 20 & 14.5 & 0.293 \\
\hline & Moderate & 14 & 12.4 & 15 & 10.9 & 0.708 \\
\hline & Massive & 18 & 15.9 & 28 & 20.3 & 0.374 \\
\hline & None/small & 81 & 71.7 & 95 & 68.8 & 0.625 \\
\hline & Moderate/massive & 32 & 28.3 & 43 & 31.2 & 0.625 \\
\hline
\end{tabular}

nab-PTX nanoparticle albumin-bound paclitaxel, RAM ramucirumab, HER2 human epidermal growth factor receptor 2, ECOG PS Eastern Cooperative Oncology Group performance status

the nab-PTX plus RAM and PTX plus RAM groups, respectively, achieved partial response, resulting in a 33.7 and $27.4 \%$ ORR, respectively $(P=0.385)$. Of note, higher DCR was observed in the nab-PTX plus RAM group compared with the PTX plus RAM group (81.9\% vs. $67.0 \%$, respectively; $P=0.016$ ) (Table 3 ).

\section{Safety}

All patients initially received full-dose RAM. The proportion of patients with initial dose reductions of nabPTX (54 patients, $47.8 \%$ ) was significantly higher than that of patients with initial dose reduction of PTX (41 patients, 29.7\% $)(P=0.003)$. During treatment, dose 
a Progression-free survival with each chemotherapy

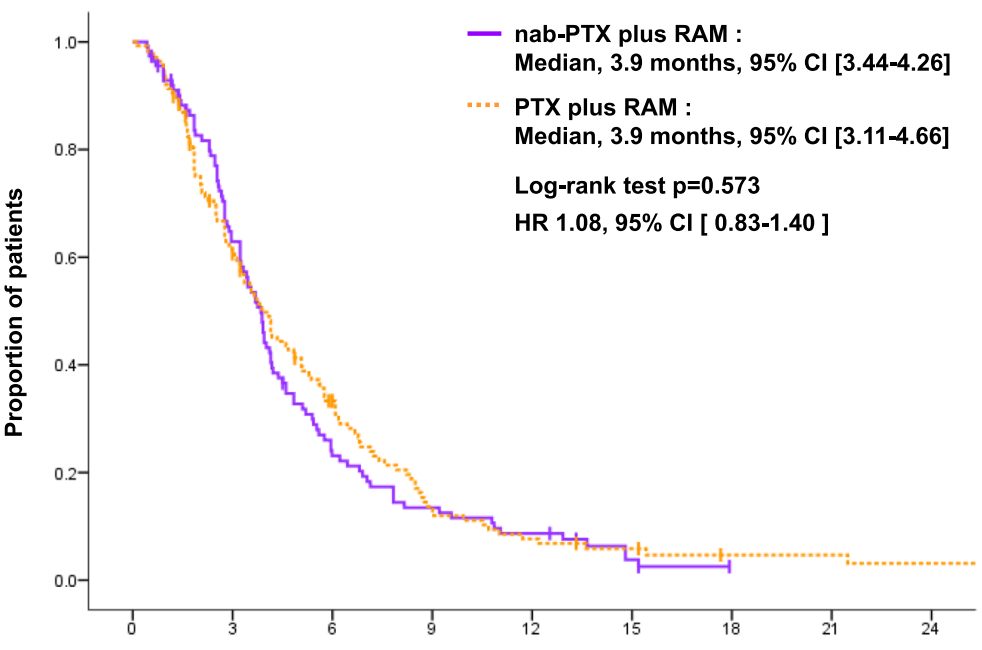

\begin{tabular}{rlllllllll} 
Number at risk & \multicolumn{10}{c}{ Progression free survival (Months) } \\
nab-PTX plus RAM & 113 & 67 & 24 & 14 & 9 & 3 & 0 & 0 & 0 \\
PTX plus RAM & 138 & 79 & 39 & 16 & 9 & 6 & 3 & 3 & 2
\end{tabular}

b Overall survival with each chemotherapy

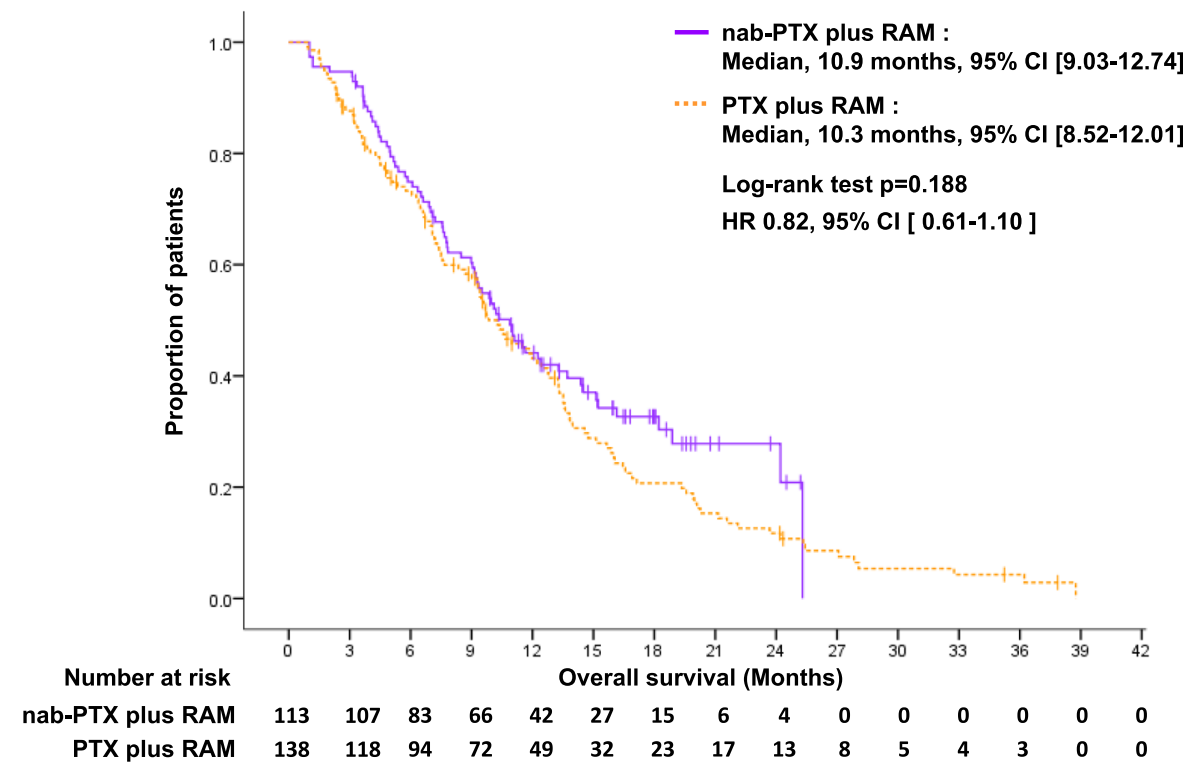

Fig. $\mathbf{2}$ a Progression-free survival with each chemotherapy. Solid line. Nab-PTX plus RAM chemotherapy. Dotted line. PTX plus RAM chemotherapy. b Overall survival with each chemotherapy. Solid line. Nab-PTX plus RAM chemotherapy. Dotted line. PTX plus RAM chemotherapy

reduction or interruption of nab-PTX or PTX occurred in $93(82.3 \%)$ and $98(71.0 \%)$ patients in the nab-PTX plus RAM and PTX plus RAM groups, respectively. The median relative dose intensity (RDI) of nab-PTX in the nab-PTX plus RAM and PTX in the PTX plus RAM group was 57.1 and 61.3\%, respectively. There was no difference in RDI of RAM between the nab-PTX plus RAM and PTX plus RAM groups (median: $98.2 \%$ vs. 97.6\%, respectively).

Treatment-related adverse events (TRAE) are listed in Table 2. Overall, $67.3 \%$ (76/113) and 63.8\% (88/138) of patients in the nab-PTX plus RAM and PTX plus RAM 
a Forest plots for subgroup analysis of progression-free survival.

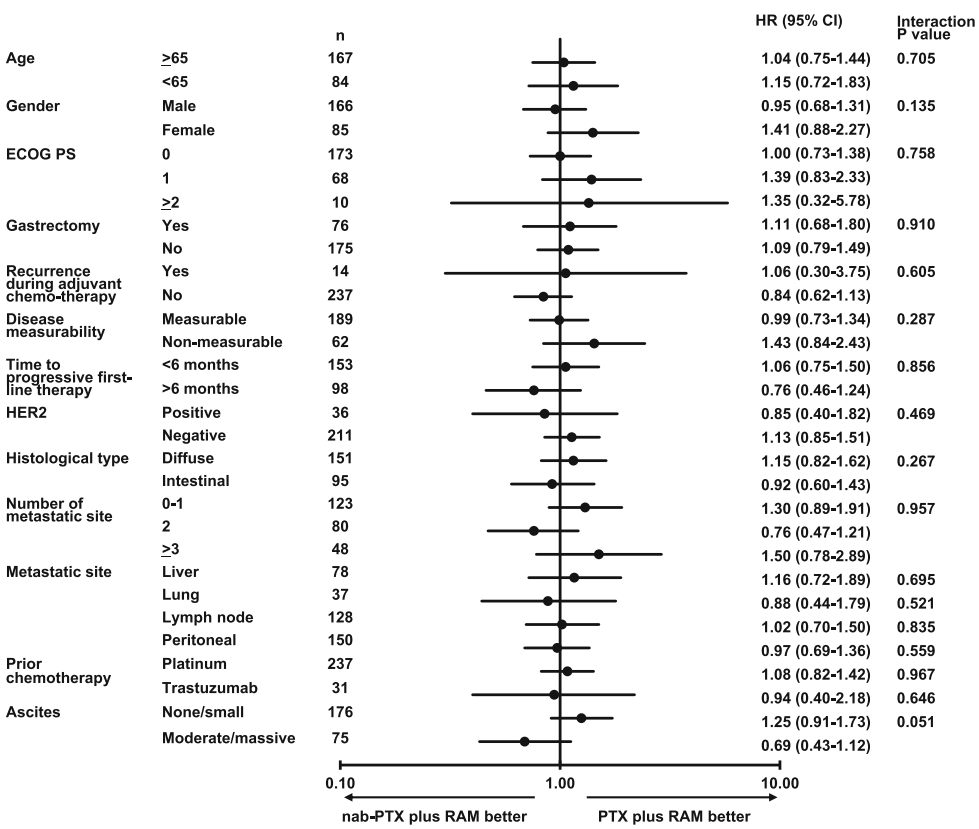

b Forest plots for subgroup analysis of overall survival.

\begin{tabular}{|c|c|c|c|c|c|c|c|}
\hline \multirow{3}{*}{ Age } & & $\mathrm{n}$ & & & & $\mathrm{HR}(95 \% \mathrm{Cl})$ & $\begin{array}{l}\text { Interaction } \\
\text { Pvalue }\end{array}$ \\
\hline & $\geq 65$ & 167 & & & & $0.90(0.63-1.31)$ & 0.372 \\
\hline & $<65$ & 84 & & $\rightarrow$ & & $0.67(0.40-1.11)$ & \\
\hline \multirow[t]{2}{*}{ Gender } & Male & 166 & & & & $0.87(0.60-1.27)$ & 0.942 \\
\hline & Female & 85 & & $\rightarrow$ & & $0.74(0.45-1.21)$ & \\
\hline \multirow[t]{3}{*}{ ECOG PS } & 0 & 173 & & & & $0.80(0.55-1.16)$ & 0.399 \\
\hline & 1 & 68 & & & & $1.09(0.63-1.88)$ & \\
\hline & $\geq 2$ & 10 & & & & $1.07(0.26-4.37)$ & \\
\hline \multirow[t]{2}{*}{ Gastrectomy } & Yes & 76 & & & & $0.57(0.31-1.02)$ & 0.086 \\
\hline & No & 175 & & & & $0.96(0.68-1.36)$ & \\
\hline \multirow{2}{*}{$\begin{array}{l}\text { Recurrence } \\
\text { during adjuvant } \\
\text { chemo-therapy }\end{array}$} & Yes & 14 & & & & $0.44(0.08-2.26)$ & 0.419 \\
\hline & No & 237 & & & & $0.84(0.62-1.13)$ & \\
\hline \multirow{2}{*}{$\begin{array}{l}\text { Disease } \\
\text { measurability }\end{array}$} & Measurable & 189 & & & & $0.81(0.58-1.14)$ & 0.543 \\
\hline & Non-measurable & 62 & & & & $0.78(0.43-1.44)$ & \\
\hline \multirow{4}{*}{$\begin{array}{l}\text { Time to } \\
\text { progressive first- } \\
\text { ine therapy } \\
\text { HER2 }\end{array}$} & $<6$ months & 153 & & & & $0.83(0.57-1.22)$ & 0.807 \\
\hline & $>6$ months & 98 & & - & & $0.76(0.46-1.24)$ & \\
\hline & Positive & 36 & & & & $0.97(0.42-2.24)$ & 0.477 \\
\hline & Negative & 211 & & & & $0.80(0.58-1.10)$ & \\
\hline \multirow[t]{2}{*}{ Histological type } & Diffuse & 151 & & & & $0.74(0.51-1.08)$ & 0.916 \\
\hline & Intestinal & 95 & & & & $0.92(0.55-1.54)$ & \\
\hline \multirow{3}{*}{$\begin{array}{l}\text { Number of } \\
\text { metastatic site }\end{array}$} & $0-1$ & 123 & & & & $0.81(0.53-1.25)$ & 0.595 \\
\hline & 2 & 80 & & & & $0.65(0.37-1.13)$ & \\
\hline & $\geq 3$ & 48 & & & & $1.26(0.67-2.39)$ & \\
\hline \multirow[t]{4}{*}{ Metastatic site } & Liver & 78 & & & & $0.90(0.52-1.57)$ & 0.723 \\
\hline & Lung & 37 & & & & $0.89(0.40-1.97)$ & 0.837 \\
\hline & Lymph node & 128 & & & & $0.90(0.59-1.36)$ & 0.583 \\
\hline & Peritoneal & 150 & & & & $0.79(0.55-1.14)$ & 0.712 \\
\hline \multirow{2}{*}{$\begin{array}{l}\text { Prior } \\
\text { chemotherapy }\end{array}$} & Platinum & 237 & & & & $0.83(0.61-1.13)$ & 0.543 \\
\hline & Trastuzumab & 31 & & & & $0.78(0.29-2.04)$ & 0.892 \\
\hline \multirow[t]{4}{*}{ Ascites } & None/small & 176 & & & & $0.85(0.59-1.23)$ & 0.836 \\
\hline & Moderate/massive & 75 & & & & $0.76(0.45-1.27)$ & \\
\hline & & 0.01 & 0.10 & 1.00 & 10.00 & 100.00 & \\
\hline & & & & & & & \\
\hline
\end{tabular}

Fig. 3 a Forest plots for subgroup analyses of progression-free survival. b Forest plots for subgroup analyses of overall survival

groups, respectively, experienced grade $\geq 3$ TRAEs. The most frequent grade $\geq 3$ TRAEs were neutropenia, leukopenia, anemia, thrombocytopenia, hypertension, and febrile neutropenia. Thirty-three (28.0\%) and 47 patients (34.1\%) in the nab-PTX plus RAM and PTX plus RAM groups, respectively, received granulocyte colony-stimulating factor, without use of granulocyte colony-stimulating factor prophylaxis in either of the groups. Although any grade of anemia, thrombocytopenia, sensory neuropathy, and fatigue were more frequently observed in the nabPTX plus RAM group, there were no significant differences in grade $\geq 3$ TRAEs between the two groups. Hypersensitivity reactions occurred in none of the 113 patients (0\%) in the nab-PTX plus RAM group and two of the 138 
Table 2 Adverse events

\begin{tabular}{|c|c|c|c|c|c|c|}
\hline & nab-PTX plus & & PTX plus RAM & & $P$ value & \\
\hline & $(N=113)$ & & $(N=138)$ & & & \\
\hline & Any grade (\%) & $\geq$ Grade $3(\%)$ & Any grade (\%) & $\geq$ Grade $3(\%)$ & Any grade & $\geq$ Grade 3 \\
\hline All adverse events & $112(99.1)$ & $76(67.3)$ & $134(97.1)$ & $88(63.8)$ & 0.254 & 0.563 \\
\hline Hematological & & & & & & \\
\hline Neutropenia & $91(80.5)$ & $64(56.6)$ & $108(78.3)$ & $76(55.1)$ & 0.659 & 0.804 \\
\hline Leukopenia & $85(75.2)$ & $34(30.1)$ & $107(77.5)$ & $48(34.8)$ & 0.667 & 0.43 \\
\hline Anemia & 105 (92.9) & $8(7.1)$ & $112(81.2)$ & 19 (13.8) & 0.007 & 0.089 \\
\hline Thrombocytopenia & $43(38.1)$ & $6(5.3)$ & $35(25.4)$ & $4(2.9)$ & 0.031 & 0.258 \\
\hline Non-hematological & & & & & & \\
\hline Sensory neuropathy & $72(63.7)$ & $2(1.8)$ & $51(37.0)$ & $0(0.0)$ & 0 & 0.202 \\
\hline Fatigue & $42(37.2)$ & $1(0.9)$ & $33(23.9)$ & $0(0.0)$ & 0.022 & 0.45 \\
\hline Anorexia & $33(29.2)$ & $1(0.9)$ & $29(21.0)$ & $1(0.7)$ & 0.134 & 0.699 \\
\hline Nausea & $17(15.0)$ & $2(1.8)$ & $18(13.0)$ & $1(0.7)$ & 0.649 & 0.425 \\
\hline Diarrhea & $7(6.2)$ & $0(0.0)$ & $14(10.1)$ & $0(0.0)$ & 0.261 & - \\
\hline Stomatitis & $10(8.8)$ & $0(0.0)$ & $14(10.1)$ & $1(0.7)$ & 0.728 & 0.55 \\
\hline Edema & $33(29.2)$ & $0(0.0)$ & $32(23.2)$ & $0(0.0)$ & 0.279 & - \\
\hline Proteinuria & $30(26.5)$ & $3(2.7)$ & $29(21.0)$ & $2(1.4)$ & 0.304 & 0.406 \\
\hline Hypertension & $30(26.5)$ & $15(13.3)$ & 27 (19.6) & $9(6.5)$ & 0.189 & 0.07 \\
\hline Febrile neutropenia & $6(5.1)$ & $6(5.1)$ & $13(9.4)$ & $13(9.4)$ & 0.221 & 0.221 \\
\hline Interstitial pneumonia & $8(7.1)$ & $3(2.7)$ & $5(3.6)$ & $3(2.2)$ & 0.219 & 0.56 \\
\hline Hypersensitivity reaction & $0(0.0)$ & $0(0.0)$ & $2(1.4)$ & $2(1.4)$ & - & - \\
\hline
\end{tabular}

nab-PTX nanoparticle albumin-bound paclitaxel, RAM ramucirumab

patients (1.4\%) in the PTX plus RAM group. These two patients were emergently hospitalized due to these hypersensitivity reactions.

TRAEs that led to treatment discontinuation were similar between the two groups: $22.1 \%$ (25/113) and 14.5\% (20/138) of the patients in the nab-PTX plus RAM and PTX plus RAM groups, respectively. The most common TRAE leading to treatment discontinuation was sensory neuropathy: $3.5 \%(4 / 113)$ and $1.4 \%(2 / 138)$ of the patients in the nabPTX plus RAM and PTX plus RAM groups, respectively.

Table 3 Overall response

\begin{tabular}{|c|c|c|c|c|c|}
\hline \multirow{2}{*}{$\begin{array}{l}\text { Best } \\
\text { response }\end{array}$} & \multicolumn{2}{|c|}{ nab-PTX plus RAM } & \multicolumn{2}{|c|}{ PTX plus RAM } & \multirow[t]{2}{*}{$P$ value } \\
\hline & $N=83$ & $\%$ & $N=106$ & $\%$ & \\
\hline$C R$ & 0 & 0 & 0 & 0 & \\
\hline$P R$ & 28 & 33.7 & 29 & 27.4 & \\
\hline SD & 40 & 48.2 & 42 & 39.6 & \\
\hline PD & 11 & 13.3 & 28 & 26.4 & \\
\hline NE & 4 & 4.8 & 7 & 6.6 & \\
\hline ORR & 28 & 33.7 & 29 & 27.4 & 0.385 \\
\hline DCR & 68 & 81.9 & 71 & 67 & 0.016 \\
\hline
\end{tabular}

nab-PTX nanoparticle albumin-bound paclitaxel, $R A M$ ramucirumab, $C R$ complete response, $P R$ partial response, $S D$ stable disease, $P D$ progressive disease, $N E$ not evaluated, $O R R$ overall response rate, $D C R$ disease control rate

\section{Discussion}

To the best of our knowledge, this is the largest cohort study to evaluate the efficacy and safety of nab-PTX plus RAM compared with PTX plus RAM as second-line treatment for patients with AGC. Our study indicated that the combination of nab-PTX plus RAM has a similar efficacy and safety profile to PTX plus RAM in patients with AGC. Although only a single-arm phase II trial has assessed the efficacy and safety of nab-PTX plus RAM, this regimen may be an option for previously treated patients with AGC. This alcohol-free regimen is linked to shorter infusion time and reduced rate of hypersensitivity reactions [13].

There were no significant differences in PFS and ORR between the nab-PTX plus RAM and PTX plus RAM groups. As real-world data, the efficacy observed in the PTX plus RAM group in our study was comparable to that recorded in the RAINBOW study [6]. The PFS and ORR in the nab-PTX plus RAM group were relatively inferior to those reported in the phase II trial of nabPTX plus RAM for patients with AGC, showing a median PFS of 7.6 months and an ORR of $54.8 \%$ [13]. However, a higher proportion of patients who received previous platinum containing regimen and/or $<6$ month of duration of first-line chemotherapy, and had 
peritoneal metastasis were included in our study. The difference in patient characteristics may have led to lower ORR and shorter median PFS compared with those noted in the clinical trial. In terms of OS, there was no significant difference observed between the two groups. However, a higher proportion of patients who received subsequent anti-PD-1/PD-L1 therapy in the nab-PTX plus RAM group contributed to the plateau of the Kaplan-Meier curve at the long-term follow-up compared with that of the PTX plus RAM group. In a subgroup analysis, PFS in patients with moderate/ massive ascites tended to be better with nab-PTX plus RAM than PTX plus RAM. The ABSOLUTE trial, which demonstrated the non-inferiority of weekly nab-PTX to weekly PTX for patients with AGC, also suggested an increased efficacy of weekly nab-PTX in patients with ascites or peritoneal metastasis $[11,16]$. Although the reason for this remains unclear, higher efficacy of nabPTX was reported in a gastric cancer preclinical model with subcutaneous and peritoneal xenografts, comparing with PTX [17]. A multicenter randomized phase II PSELECT trial of nab-PTX plus RAM versus PTX plus RAM as second-line therapy for AGC patients with peritoneal dissemination (WJOG10617G, jRCTs031180022) is underway and may confirm this observation.

The general safety profile of nab-PTX plus RAM was manageable and comparable to that of PTX plus RAM. Although anemia and fatigue (any grade) were more frequent in the nab-PTX plus RAM group, there was no difference in grade $\geq 3$ of those adverse events between the two groups, and none of the patients discontinued treatment due to these adverse events. The incidence of sensory neuropathy was also significantly higher in the nab-PTX plus RAM group. However, only 3.5 and 1.4\% of patients were forced to discontinue nab-PTX and PTX, respectively. In the phase II trial of nab-PTX plus RAM, $76.7 \%$ of patients experienced grade $\geq 3$ of neutropenia. In our study, a relatively lower proportion of patients (56.6\%) experienced this adverse event. The initial dose reduction of nab-PTX in $47.8 \%$ of patients in our study may have resulted in the lower frequency of grade $\geq 3$ neutropenia; however, importantly, the median RDI was similar to that observed in the phase II trial [13]. These findings indicated that appropriate dose modification enables treatment continuation, irrespective of nab-PTX plus RAM or PTX plus RAM. Of note, there was no occurrence of hypersensitivity reactions in the nab-PTX plus RAM group with premedication of only chlorpheniramine. Two patients experienced grade 3 hypersensitivity reactions in the PTX plus RAM group and required emergent hospitalization despite adequate premedication. The incidence of infrequent hypersensitivity reactions in patients receiving nab-PTX was consistent with that noted in the ABSOLUTE trial [12].
Nab-PTX was suitable for shorter-time infusion without premedication. The incidence of specific TRAEs related to RAM was similar in both groups, and there were no unexpected TRAEs observed in our study.

This study had several limitations. Firstly, this was a non-randomized retrospective study performed in a single institution with a limited sample size. Secondly, there was a shorter follow-up time in the nab-PTX plus RAM group compared with that of the PTX plus RAM due to the approval of nab-PTX in 2017. Finally, all patients enrolled in this study were Japanese. Although the indication of nab-PTX was approved not for gastric cancer but for breast cancer, non-small cell lung cancer, and adenocarcinoma of pancreas by Food and Drug Administration (FDA) and European Medicines Agency (EMA), recently, a single-arm phase II trial of nab-PTX plus RAM for patients with AGC conducted in the United States of America suggested acceptable safety profiles [18]. These data support the results of our study for the application of this regimen to all patients, regardless of race.

\section{Conclusion}

In conclusion, nab-PTX plus RAM may be a useful treatment option, along with PTX plus RAM, as secondline treatment for patients with AGC, especially in case of known hypersensitivity to PTX or alcohol allergy.

\section{Supplementary Information}

The online version contains supplementary material available at https://doi. org/10.1186/s12885-020-07614-6.

Additional file 1: Table S1. Subsequent chemotherapy.

\section{Abbreviations}

Nab-PTX: Nanoparticle albumin-bound paclitaxel; PTX: Paclitaxel; AGC: Advanced gastric cancer; RAM: Ramucirumab; PFS: Progression-free survival; Cl: Confidence interval; HR: Hazard ratio; OS: Overall survival; ORR: Overall response rate; DCR: Disease control rate; PD-1: Programmed cell death 1; PD-L1: Programmed cell death ligand 1

\section{Acknowledgements \\ The authors would like to thank Enago (www.enago.jp) for the English language review.}

\footnotetext{
Authors' contributions

$\mathrm{MO}$ initiated the study, participated in its design and data collection, performed statistical analyses, and drafted the manuscript. DK was responsible for the study conception and helped manuscript writing and data collection. KD, AK, and KS edited manuscript. TY and TK helped manuscript writing and participated in manuscript editing. All authors read and approved the final manuscript.
}

Funding

There was no funding for this study. 


\section{Availability of data and materials}

The evaluation data set analyzed in the current study is not available publicly. However, the data are available from the corresponding author on request.

\section{Ethics approval and consent to participate}

Study protocol was approved by the institutional review board (National Cancer Center IRB, ref. 2019-137). Informed consent requirement was waived due to the study's observational retrospective design, with an opt-out opportunity provided at the institution's website.

\section{Consent for publication}

Not applicable.

\section{Competing interests}

DK reports receiving honoraria from Takeda, Chugai, Lilly, Merck Serono, Taiho, Sysmex outside of this work. AK reports receiving research funding from Taiho, Ono, Sumitomo Dainippon and MSD outside of this work. TY reports receiving research funding from Novartis, MSD, Sumitomo Dainippon, Chugai, Sanofi, Daiichi-Sankyo, Parexel, Ono, Glaxo Smith Kline, and Boehringer Ingelheim. KS reports paid consulting or advisory roles for Astellas, Lilly, Bristol-Myers Squibb, Takeda, Pfizer, Ono, MSD, Taiho, Novartis, Abbie, and Glaxo Smith Kline; honoraria from Novartis, Abbie, and Yakult; and research funding from Astellas, Lilly, Ono, Sumitomo Dainippon, Daiichi Sankyo, Taiho, Chugai, MSD and Medi Science.

\section{Author details}

'Department of Pharmacy, National Cancer Center Hospital East, Kashiwa, Japan. ${ }^{2}$ Department of Gastrointestinal Oncology, National Cancer Center Hospital East, 6-5-1 Kashiwanoha, Kashiwa, Chiba 277-8577, Japan.

Received: 28 April 2020 Accepted: 3 November 2020

Published online: 16 November 2020

\section{References}

1. Feely J, Soerjomataram I, Ervik M, Dikshit R, Eser S, Mathers C, et al. GLOBOCAN 2012 v1.1, cancer incidence and mortality worldwide: IARS cancer base no. 11. Lyon: International Agency for Research on Cancer; 2014.

2. National Comprehensive Cancer Network. NCCN clinical practice guidelines in oncology gastric cancer. Version 1. 2020.

3. Japanese Gastric Cancer Association. Japanese gastric cancer treatment guideline 2018 (ver.5).

4. Smyth EC, Verheij M, Allum W, Cunningham D, Cervantes A, Arnold D, et al. Gastric cancer: ESMO clinical practice guidelines for diagnosis, treatment and follow-up. Ann Oncol. 2016;27(5):38-49.

5. Muro K, Van Cutsem E, Narita Y, Pentheroudakis G, Baba E, Li J, et al. PanAsian adapted ESMO clinical practice guidelines for the management of patients with metastatic gastric cancer: a JSMO-ESMO initiative endorsed by CSCO, KSMO, MOS, SSO and TOS. Ann Oncol. 2019;30:19-33.

6. Wilke H, Muro K, Van Cutsem CE, Oh SC, Bodoky G, Shimada Y, et al. Ramucirumab plus paclitaxel versus placebo plus paclitaxel in patients with previously treated advanced gastric cancer or gastro-oesophageal junction adenocarcinoma (RAINBOW): adouble-blind, randomized phase 3 trial. Lancet Oncol. 2014;15:1224-35.

7. Shitara K, Muro K, Shimada Y, Hironaka S, Sugimoto N, Komatsu Y, et al. Subgroup aanalysis of the safety and efficacy of ramucirumab in Japanese and Western patients in RAINBOW: a randomised clinical trial in second-line treatment of gastric cancer. Gastric Cancer. 2016;19:927-38.

8. Gelderblom H, Verweij J, Nooter K, Sparreboom A, Cremophor EL. The drawbacks and advantages of vehicle selection for drug formuration. Eur J Cancer. 2001;37:1590-8.

9. Weiss RB, Donehower RC, Wiernik PH, Ohnuma T, Gralla RJ, Trump DL, et al. Hypersensitivity reactions from taxol. J Clin Oncol. 1990;8:1263-8.

10. Ibrahim NK, Samuels B, Page R, Doval D, Patel KM, Rao SC, et al. Multicenter phase II trial of ABI-007, an albumin-bound paclitaxel, in women with metastatic breast cancer. J Clin Oncol. 2005:23:6019-26.

11. Sasaki Y, Nishina T, Yasui H, Goto M, Muro K, Tsuji A, et al. Phase II trial of nanoparticle albumin-bound paclitaxel as second-line chemotherapy for unresectable or recurrent gastric cancer. Cancer Sci. 2014;105:812-7.
12. Shitara K, Takashima A, Fujitani K, Koeda K, Hara H, Nakayama N, et al. Nab-paclitaxel versus solvent-based paclitaxel in patients with previously treated advanced gastric cancer (ABSOLUTE): an open-label, randomized, non-inferiority, phase 3 trial. Lancet Gastroenterol Hepatol. 2017;2:277-87.

13. Bando $H$, Shimodaira H, Fujitani K, Takashima A, Yamaguchi K, Nakayama N, et al. A phase II study of nab-paclitaxel in combination with ramucirmub in patients with previously treated advanced gastric cancer. Eur J Cancer. 2018; 91:86-91.

14. U.S. Department of health and human survices. Common Terminology Criteria for Adverse Events. version 4.032010.

15. Matsumoto H, Kawazoe A, Shimada K, Fukuoka S, Kuboki Y, Bando H, et al. A retrospective study of the safety and efficacy of paclitaxel plus ramucirmab in patients with advanced or recurrent gastric cancer with ascites. BMC Cancer. 2018;18:120

16. Takashima A, Shitara K, Fujitani K, Koeda K, Hara H, Nakayama N, et al. Peritoneal metastasis as a predictive factor for nab-paclitaxel in patients with pretreated advanced gastric cancer: an exploratory analysis of the phase III ABSOLUTE trial. Gastric Cancer. 2019;22:155-63.

17. Kinoshita J, Fushida S, Tsukada T, Oyama K, Watanabe T, Shoji M, et al. Comparative study of the antitumor activity of Nab-paclitaxel and intraperitoneal solvent-based paclitaxel regarding peritoneal metastasis in gastric cancer. Oncol Rep. 2014;32(1):89-96. https://doi.org/10.3892/or.2014. 3210 Epub 2014 May 23. PMID: 24859429.

18. Bendell JC, Percent IJ, Weaver RW, Chua CC, Xiong HQ, Cohn AL, et al. phase II study of nab-paclitaxel plus ramucirmab for the second-line treatment of patients with metastatic gastroesophageal cancer. J Clin Oncol. 2020;38:4 suppl 365

\section{Publisher's Note}

Springer Nature remains neutral with regard to jurisdictional claims in published maps and institutional affiliations.

Ready to submit your research? Choose BMC and benefit from:

- fast, convenient online submission

- thorough peer review by experienced researchers in your field

- rapid publication on acceptance

- support for research data, including large and complex data types

- gold Open Access which fosters wider collaboration and increased citations

- maximum visibility for your research: over $100 \mathrm{M}$ website views per year

At BMC, research is always in progress.

Learn more biomedcentral.com/submissions 